\title{
Tunes in Free Variation and Sequentially Determined Pitch Alignment: Evidence from Interactional Organisation
}

\author{
Marianna Kaimaki \\ University of York \\ mk502@york.ac.uk
}

\begin{abstract}
Results arising from a study of the prosodic organisation of everyday talk in Greek suggest that 'falling' and 'rising' tunes might occur in free variation in certain interactional contexts. They also show that, at least for Greek, pitch alignment of rising tunes might be interactionally driven. I explore these possibilities by examining the organisation of two interactional sequences: a) response-to-summons turns (i.e. the first utterance by the recipient of a call) at the openings of Greek telephone calls, b) sequences involving the Greek continuer ne. Analysis of the first data set of response-to-summons turns suggests that the choice of falling or rising tune does not appear to have consequences for the design or subsequent development of the talk. Nor is there evidence in the interactional behaviour of the participants that the choice conveys a difference in pragmatic nuance. Analysis of the second data set shows that pitch alignment of rising tunes might be dependent on the interactional function and/or lexical design of the turn they occur in.

I argue that choice of tune-type in this interactional context is related to particular lexical selections and that pitch alignment is related to interactional structure and composition of the turn.
\end{abstract}

\section{Keywords}

free variation, intonation, pitch alignment, pragmatics, prosody, response-to-summons turn, telephone calls, tune-type

\section{Introduction}

This article arises from trying to understand the way in which phonetic features and phonological patterns are shaped by the interactional sequential organisation of everyday talk. The interactional aspects of analysis in this article are informed by research in Conversation Analysis (Goodwin et al 1990, ten Have 1999, Heritage 1984, Hutchby et al. 1998, Sacks et al. 1974). This manifests itself in three main ways. First, the data analysed arise from naturally occurring spontaneous everyday conversation - all the talk examined is being done by the participants for their own (not the researcher's) purposes. 
Second, in establishing comparable stretches of talk for analysis, primacy is given to where in the interactional sequence the talk occurs and what action(s) that talk is implementing. Third, in attempting to establish the functions and 'meanings' of particular stretches of talk, account is taken of the ways in which that talk is treated by a co-participant.

Local (2007: 1) suggests that 'phonetic aspects of language should in the first instance be understood as shaped by interactional considerations'. This suggests that if our analyses of the pitch characteristics of language are sensitive to interactional-sequential organisation, we may be able to understand the phonological organisation of pitch phenomena (e.g. intonational 'contrast') in rather different ways. Not only might we arrive at a different interpretation of the work pitch is engaged in, but also produce an empirically robust interpretation of intonational 'meaning'. One of the issues which is explored in this article is the relationship between interactional function and intonational 'contrast'. Analyses of phonological intonational contrast (e.g., the functional difference between falling and rising contours) routinely draw on intuitive interpretation, often of constructed or decontextualised data. Such data may not necessarily refiect how phonological contrast is established in real talk-ininteraction. In my analyses I attempt to avoid appeals to intuition and provide a sequential-contextual account of the functional and contrastive potential of pitch phenomena.

One of the resources that speakers bring to bear in constructing and conveying linguistic meaning is variation in the phonetic shape of their talk. This article considers the ways in which phonetic aspects of turns at talk in Greek telephone conversations are implicated in the construction of meaning. In particular, by examining the pitch characteristics of particular turns at talk in particular interactional sequences, it aims to make a contribution to our understanding of the ways in which pitch phenomena vary, function, and are constrained in everyday talk. By taking account of the sequential development of talk, the analysis tries to understand the role of pitch accents in signalling transition relevance and how and where pitch accents contrast ${ }^{1}$.

This article is organised as follows. Section 2 sets out the motivations behind the research, while Section 3 provides a detailed examination of the phonetic design of first spoken turns (T1) in Greek telephone calls. Section 4 examines the relationship between the phonetic design of T1 turns and the actions implemented at speakers' next turn. In Section 5, some of the phonetic and sequential-interactional characteristics of oriste ('here you are', 'at your orders')

1 'Transition relevance' refers to places of grammatical, pragmatic and prosodic completion in talk where it becomes relevant and appropriate for a coparticipant to begin speaking). 
and ne ('yes') tokens in non-T1 position in Greek telephone calls are explored. Section 6 examines the interactional function and phonetic design of non-T1 $n e$ and oriste tokens. Finally, Section 7 provides an overview of the principal findings and draws some conclusions.

\section{Motivation}

Accounts of the linguistic organisation of pitch in Greek have not really engaged with the everyday talk of ordinary speakers. For example, most current accounts of pitch organisation in Greek (e.g. Arvaniti and Baltazani 2005; Arvaniti, Ladd, and Mennen 2006; Baltazani 2006) rely principally on read and experimental data to provide material for analysis. In contrast, the data explored here arises from a corpus of naturally occurring talk in telephone calls between Greek speakers.

\section{$3 \mathrm{~T} 1$ in Greek}

This section examines the phonetic design of first spoken turns (T1) in telephone call openings. I employ 'T1' paralleling Schegloff's (1979) use of 'T2' to indicate the first spoken turn in telephone calls. In particular, I explore the details of phonetic variation in such turns and consider the role of pitch contours (and other phonetic features) in signalling transition relevance. I also consider whether particular pitch-contour shapes deployed at T1 are consequential for the further unfolding of conversation - that is, whether different phonetic designs of T1 result in different uptakes by the recipient and producer of the second turn (T2).

Although the sequential design of call openings has received extensive analytic attention in the Conversation Analysis Literature (e.g. HoutkoopSteenstra 1991; Sacks 1992a,b; Schegloff 1986), the phonetic design of these openings has not received the same degree of scrutiny (but note CouperKuhlen 2001, Danby et al. 2009, Szczepek 2009). It could be argued that telephone call openings are highly stylised formulations, the study of which would not offer any further advances into the research of talk-in-interaction or of the phonetic design of talk. However, Schegloff notes that despite the apparently 'routine' structure and patterning of telephone call openings, failure to produce the basic components of the pattern (e.g. absence of a T1) disrupts the smooth flow of conversation. This results for instance in participants having to re-establish and re-confirm that the 'channel of communication' 
(Schegloff 1986) is open or that the person at the other end of the phone is indeed the one they wish to speak to. As Schegloff notes "Routine' openings in which 'nothing' happens need ... to be understood as achievements arrived at out of a welter of possibilities for preemptive moves or claims, rather than a mechanical or automatic playings [sic] out of pre-scripted routines." (1986: 117).

Greek is reported to have a prosodic system with five pitch accents (Arvaniti and Baltazani 2005). Published data on Greek telephone calls (Antonopoulou and Sifianou 2003; Pavlidou 2000) suggests that T1 turns are largely restricted to single Turn Constructional Unit (TCU) ${ }^{2}$ items. If one-unit turns are the routine (or only) possible choice available in T1 position in Greek telephone openings, it is reasonable to expect that the system of pitch accents operating at $\mathrm{T} 1$ position would be restricted.

The data consists of 9 hours of telephone calls made between Greek speaking friends and family members. 45 different participants answering the phone were involved. Data was collected in the north of Greece (Thessaloniki) between December 2005 and January 2006. Standard Modern Greek ${ }^{3}$ was recorded as spoken in the city of Thessaloniki by informants who were born in and are residents of Thessaloniki. There are two speakers who do not fall into this group. One is from Kozani (where a northern dialect is spoken) and has been living in Thessaloniki for 50 years and the other was born and raised in Thessaloniki but has been living in the South for more than 40 years. Neither of these speakers exhibited prosodic patterns which differed from those of the other speakers. The data yielded 112 calls with fully complete recorded openings. Table 1 shows percentages of the kinds of T1s that were encountered in the data.

Table 1. Greek T1s: number of instances

\begin{tabular}{lcl}
\hline Greek call openings & $\mathrm{N}$ & $\%$ \\
\hline oriste & 57 & $51 \%$ \\
ne & 34 & $30 \%$ \\
Other & 21 & $19 \%$ \\
Total & 112 & $100 \%$ \\
\hline
\end{tabular}

${ }^{2}$ TCU stands for 'Turn Constructional Unit' which is used in CA literature to refer to units out of which turns at talk are constructed.

3 The term Modern Greek encapsulates the Standard Modern Greek (SMG) and the Modern Greek dialects. SMG is heard in the two major urban centres, Athens and Thessaloniki. Some differences between the two include the indirect object which can be in the accusative in the variety of Thessaloniki but only in the genitive in the variety spoken in Athens (for more information on Standard Modern Greek and Modern Greek dialects see Babiniotis 1998, Browning 1983, Charalambakis 1992, Mackridge 1985, Tzitzilis 2000). 


\subsection{Variation in $T 1$ format}

The most common T1 format is a single TCU and single lexical item - oriste (literal meaning: 'here you are', 'at your orders'). This accounts for half of the cases. The second most common choice is the lexical item ne (literal meaning 'yes') which accounts for slightly more than a third of the instances. In the remaining 21 ('Other') cases participants employ one of the following single TCU lexical items: parakalo (8/112), (literal meaning 'you are welcome'), ne oriste (2/112), embros (1/112), (literal meaning 'move forward'), ne embros (1/112), legete (1/112), (literal meaning 'tell me', in plural form) and ne ne $(1 / 112)$. Finally, there are five instances where the person called knew who the caller was - either because the call was made to a mobile or because the call was a 'call me back' one. In these cases the lexical item used was ela (literal meaning 'come'), an item more regularly found in 'T2' position as a way of displaying recognition. There are also two cases of 'institutional' telephone calls where the phone was answered with a multi-unit turn. Fragments (1) and (2) exemplify transitions from T1 to T2 where the two most frequent formats (ne and oriste) are employed.

(1) $\mathrm{GMJM}^{4}$

$1 \quad((\mathrm{RING}))$

2 Tim: oriste $\downarrow$

at your orders

hello

3 (.)

4 Pam: ela Timmy

come (imp) NAME (dim)

hi Timmy

(2) GPM

$1 \quad((\mathrm{RING}))$

2 Meg: .h ne^h

yes

yes

3 Pam: ela irthe

come (imp) came ( $3^{\text {rd }}$ sing)

hi she's here

In fragment (1), Tim's answer to the summons consists of a single lexical TCU which, after a micropause, is followed at T2 by Pam's reciprocal greeting and

${ }^{4}$ Data fragments are labelled by a letter code which identifies the audio file for each call. Pseudonyms are used to conceal participants' identities. The reason for using foreign names instead of Greek, more naturalistic ones is that three character (letter) names were sought according to standard CA practice and most Greek names are considerably longer. 
identification by first name of the call answerer. In fragment (2), Meg issues a different single lexical TCU 'ne' in T1 position. Pam's T2 turn begins immediately after Meg's first turn has come to completion and consists of a greeting plus a news-telling.

\subsection{Phonetic analysis of T1 turns}

As was indicated, oriste is the favoured lexical choice in T1 position accounting for just over half (57/112) of the first turns in the data-set. Virtually all of the tokens (52/57) are produced with a falling contour which typically ends low in the speaker's range. However, there are 5 instances of oriste produced with a final rise.

The bulk of the T1 oriste tokens begin with a narrow rise to mid or slightly lower than mid in the speaker's range aligned with the first two syllables of the word. This is followed by a step down to low in the speaker's range. In the 5 cases where a final rising pitch contour is employed, the tokens begin with a stretch of relatively level pitch below the mid of the speaker's range aligned with the first two syllables. This is followed by a rise which ends above mid in the speaker's range. Fragment (3) exemplifies a 'falling' oriste T1 and fragment (4) a 'rising' oriste T1. Figures 1 and 2 show pitch traces of the T1 turn of fragment (3) and Figures 3 and 4 pitch traces of the T1 turn of fragment (4).

(3) GT

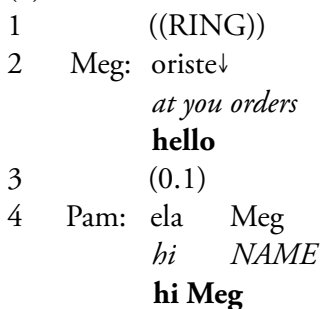

The pitch trace in Figure 1 exemplifies the canonical shape of T1 falling oriste tokens. We observe an initial pitch, typically just below the speaker's mid range (here $201 \mathrm{~Hz}-1$ semitone below the middle of the speaker's range — see Figure 2), which remains level (range $=0.9 \mathrm{st}$ ) during the first vocoid ${ }^{5}$. This is

\footnotetext{
5 'Vocoid' is a term introduced by Pike (1943) in an attempt to distinguish between the phonetic and phonological use of the term 'vowel'. In Abercrombie's words: 'A vocoid is a segment with a stricture of open approximation, with or without a velic closure, and with central passage of the air-stream.' (1967: 80).
} 


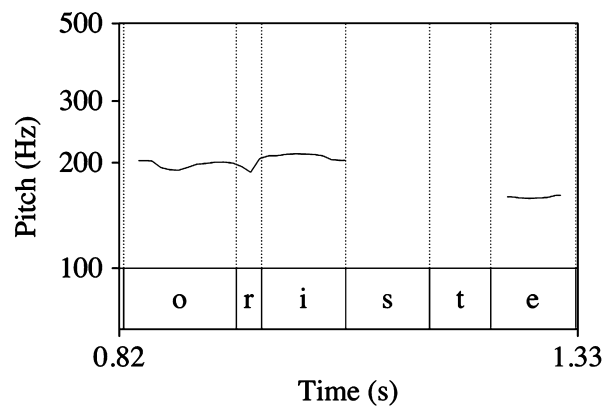

Figure 1. Pitch trace of falling oriste (GT)

TL 529

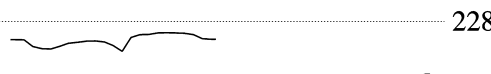

BL 75

Figure 2. Pitch trace of falling oriste, scaled to speaker range (GT)

followed by a 2 semitone step up to $212 \mathrm{~Hz}$ and the pitch remains almost level during the production of the second syllable. Finally, there is a step down to $158 \mathrm{~Hz}$ and pitch remains level (range $=0.7 \mathrm{st}$ ) for the remainder of the final vocoid. The fall over the second and third syllables is 5 semitones. The whole pitch movement has a range of 5 semitones and is produced slightly below the mid of the speaker's range. The mean pitch range for falling T1 oriste tokens is 10 semitones $(\max =18 \mathrm{st} ; \min =4 \mathrm{st} ; \mathrm{SD}=4)$.

(4) HST

$1 \quad$ ((RING))

2 Ron: oriste^

at your orders

hello

3 Tim: .hh (.) ela Ron hronia pola

hi NAME years many

hi Ron best wishes

4 (.) Stavrou

SURNAME

it's Stavrou 


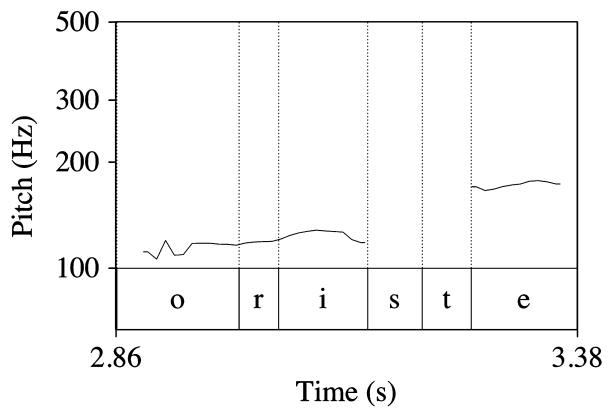

Figure 3. Pitch trace of rising oriste (HST)

$\mathrm{TL}$ 248

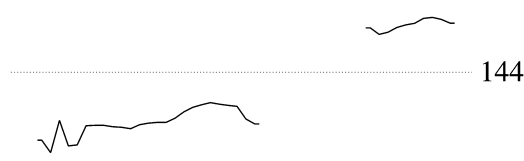

BL $-77$

Figure 4. Pitch trace of rising oriste, scaled to speaker range (HST)

Figure 3 illustrates a rising oriste token. The word begins with an initial level pitch at $119 \mathrm{~Hz}, 3$ semitones below mid in the speaker's range, which remains level (range $=0.3 \mathrm{st}$ ) for the duration of the first vocoid. Then there is a rise of 2 semitones to $128 \mathrm{~Hz}$, and the pitch remains almost level for the duration of the second syllable. Finally, there is a step up of 5 semitones to above mid in the speaker's range and the $\mathrm{F}_{0}$ remains level at approximately $172 \mathrm{~Hz}$ over the course of the last vocoid. The mean range for rising T1 oriste tokens is 13 semitones $(\max =17 \mathrm{st} ; \min =7 \mathrm{st} ; \mathrm{SD}=4)$.

The second most common lexical choice in first turn position is 'ne' which accounts for 34/112 of the instances. In all cases of T1 ne there is a rise in pitch during the vocoid ending mid or high in the speaker's range. The mean range for final rising contours associated with T1 'ne' is 12 semitones $(\max =24 s t, \min =6 s t, S D=4)$. Figures 5 and 6 provide illustrative pitch traces for the T1 'ne' token of fragment (6). 
(5) TL

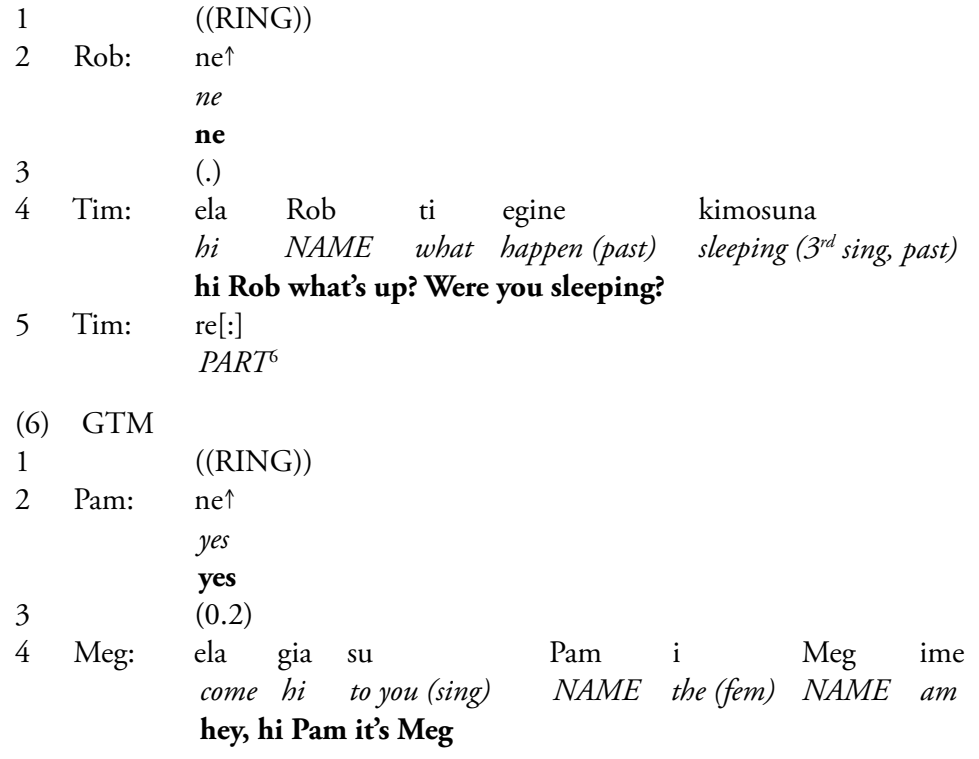

Figures 5 and 6 show pitch traces for Pam's T1 ne in fragment 6 . The initial pitch starts around the middle of the speaker's range and remains level over the course of the nasal and into the early part of the vocoid. This is followed by a rise of 9 semitones which ends 9 semitones above the mid in the

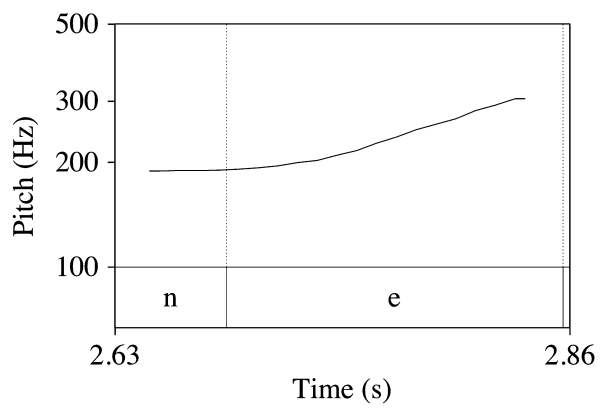

Figure 5. Pitch trace of ne female speaker (GTM)

${ }^{6}$ I use PART [particle] as a general term for phonetic events used as hesitation markers or being involved in repair sequences or news receipts. 
$\mathrm{TL}$ 490

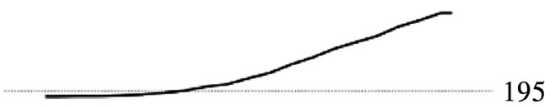

BL 76

Figure 6. Pitch trace of ne female speaker, scaled to speaker range (GTM)

speaker's range. These traces show that there is a considerable rise which occurs over the course of the whole vocoid or during the last part of the vocoid which always ends above the middle of the speaker's range. The rising contours associated with T1 'ne' show a characteristic alignment with the articulatory material such that the turning point $\left(\mathrm{TP}^{7}\right)$ of the rise occurs on average $75 \mathrm{~ms}$ $(34 \%)$ after the onset of the vocoid of the token $(\max =120 \mathrm{~ms}, 47 \%$; $\mathrm{min}$ $=16 \mathrm{~ms}, 8 \%$; $\mathrm{SD}=25)$.

\subsection{Function of pitch in the design of $T 1$}

It would appear that the primary function associated with the final pitch contours in Greek T1 turns is to project a possible completion of the current turn. Four observations support such a claim:

1. in all cases, the T1 producer stops speaking after producing one of these pitch contours. This provides evidence that these turns are designed as complete;

2. following the production of one of these pitch contours, the caller produces a T2. In producing an appropriate (fitted) next turn following T1, the caller displays an orientation to the completeness of T1. This is evidence that these turns are treated as complete;

3. transition to T2 is accomplished without occurrence of any kind of overlap. This provides evidence that the T2 producer is orienting to the whole of the production (and therefore to the whole of the pitch contour) before speaking;

7 TP refers to the turning point (TP) of a rising pitch contour (Welby and Loevenbruck 2006). Although it is not unproblematic (see e.g. Xu 1998), the TP (onset) of rises associated with rising tokens was taken to be defined as the F0 minimum immediately before the rise. 
4. T2 turns are frequently placed in close temporal proximity to T1. This provides evidence that the phonetic design of $\mathrm{T} 1$ provides sufficient information to signal transition relevance.

It could be argued that observation (3) above concerning the lack of overlap could simply be the result of other factors rather than any design features of T1. For instance, it might be argued that the caller needs time to process what they have heard in order to recognise the answerer. As a result they simply wait until the T1 producer has stopped talking before beginning to talk themselves. However, while there are cases with short gaps between T1 and T2 (e.g. fragments 1 and 3), it is not the case that callers always wait for such a gap before speaking. Nor is it easy to sustain such a position in the light of fragments such as 2, 4, or 7 and 8 where, as noted in observation (4), the callers' T2 is placed in close temporal proximity to T1. In these cases, there is no evidence that callers are waiting for the answerer to stop talking. Rather they are able to project precisely the point at which they can start talking without being in overlap. Indeed in fragments 7 and 8 the caller's T2 begins in 'extreme' temporal proximity (indicated by the ' $=$ ' 'latched' notation (Jefferson 1973), as soon as possible after the T1 (without the 'beat of silence' typically associated with such transitions; Schegloff 2000).

(7) DHEC

$1 \quad((\mathrm{RING}))$

2 Tim: oriste $\downarrow=$

at your orders

hello

3 Meg: =ela gi

su $\quad \mathrm{Ti}[\mathrm{m}]$

hey, hi Tim

NAME

(8) $\mathrm{HI}$

$\begin{array}{lll}1 & \text { Lea: } & ((\mathrm{RING})) \\ & \mathrm{ne} \uparrow= \\ \text { yes } \\ \text { hello }\end{array}$

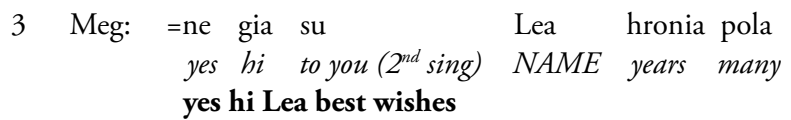

That these speakers are able to abut their talk to that of their co-participants shows that they do not need to wait for a gap of silence following T1 to let them know that $\mathrm{T} 1$ is complete. It is more plausible that there are (phonetic) details inherent in Tim's and Lea's T1s that project a point of possible completion at 


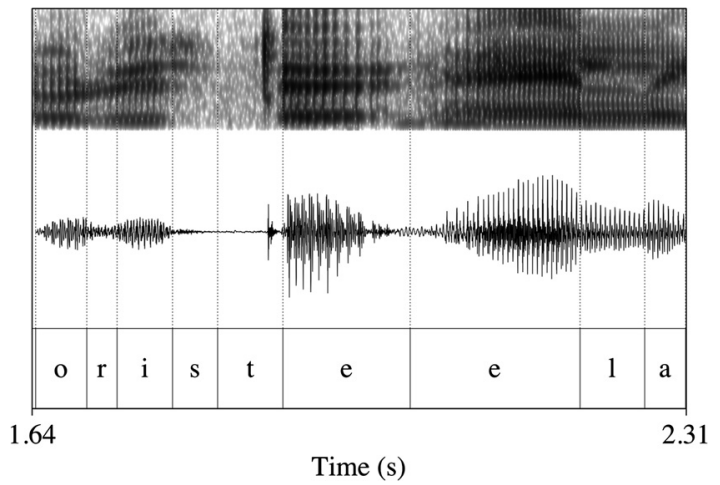

Figure 7. Spectrogram and waveform showing 'extreme' temporal proximity between T1 and T2 (DHEC)

the end of oriste in fragment (7) and ne in fragment (8). Figure 7 provides a visual impression of the 'extreme temporal proximity' of fragment (7).

\subsection{Ne oriste T1}

It could be argued that native speakers of Greek would know the kinds of TCU that one can produce at T1 position and, as they tend to be single lexical items, projection of turn-endings would be straightforward. However, in fragments (9) and (10), the production of a recognisable T1 ne does not result in talk by the co-participant but in more talk by the ne-producer. Examination of the prosodic shape of such turns shows that the pitch characteristics associated with ne in fragments (9) and (10) are different from those evidenced in T1 turns designed as a single lexical item ne. This suggests that prosodic resources may be used in projecting transition relevance. Another reason for proposing that prosody is directly implicated in projecting a transition relevance point in these turns is that syntactic and semantic resources are not available at this point in the structure to potential producers of T2s. That is, there is nothing in the lexical items oriste or ne per se that could signal to the caller that these utterances are syntactically and pragmatically complete. In the present corpus there are two T1 turns which consist of 'ne+oriste'. These are shown in fragments (9) and (10):

(9) TNM

$\begin{array}{rll}1 & \text { Rob: } & (\text { ne oriste } \uparrow \\ & \text { yes at your orders } \\ \text { hello }\end{array}$


3 Tim: ela Rob kala ise

hi NAME good are

hi Rob how are you?

4 Rob: kala Tim

good NAME

$\operatorname{good}$ Tim

(10) $\mathrm{TPOH}$

$1 \quad((\mathrm{RING}))$

2 Rob: ne oriste^ $\mathrm{h}$

yes at your orders

hello

3 Tim: ela Rob

hi NAME

hi Rob

4 Rob: ela

hi

hi

If the simple production of the lexical item ne in T1 was sufficient to signal transition relevance, Tim could have legitimately and unproblematically come in after the completion of ne (which, after all, is the second most common way of issuing a first turn in Greek). However, Tim does not come in after $n e$ but immediately after oriste. By not coming in after $n e$, Tim displays an orientation to Rob's T1 being incomplete at that point. Note that Rob treats Tim's turn at line 2 as unproblematic and responds to Tim's candidate recognition and 'how-are-you' with a fitted response. Although both these fragments involve the same interactants, it is important to note that Rob does not only design his 'response to summons' T1 with ne oriste. Tim has encountered him producing a range of tokens in $\mathrm{T} 1$ position including standalone ne.

In both cases of ne oriste, the phonetic characteristics of ne are strikingly different from those in openings where ne occupies the whole T1. The token is noticeably short $(154 \mathrm{~ms}$ in fragment (14) and $119 \mathrm{~ms}$ in fragment (15) with the vocoid occupying $55 \%$ and $51 \%$ respectively of the token). The vocoid of ne typically begins with a schwa-like quality and moves without cessation of voicing into a back open quality for the beginning of oriste. The pitch contour associated with the token is strikingly different compared to pitch events evidenced over single lexical TCU consisting of ne. Figures 8, 9 and 10 visualise this for fragment (9). The pitch contour associated with ne is below mid in the speaker's range (see figure 10) and the overall rise in pitch aligned with the vocoid is narrow (1 semitone for fragment (9))). It is only when the call answerer produces a rising contour which ends above mid in his pitch range 
that his co-participant begins (without a gap) to speak and produce a display of recognition - 'ela Rob'.

None of the standalone T1 ne tokens in the corpus exhibit such phonetic characteristics. All standalone T1 tokens involve an appreciable rise and the token is noticeably long. It is evident, then, that in producing a short vocoid

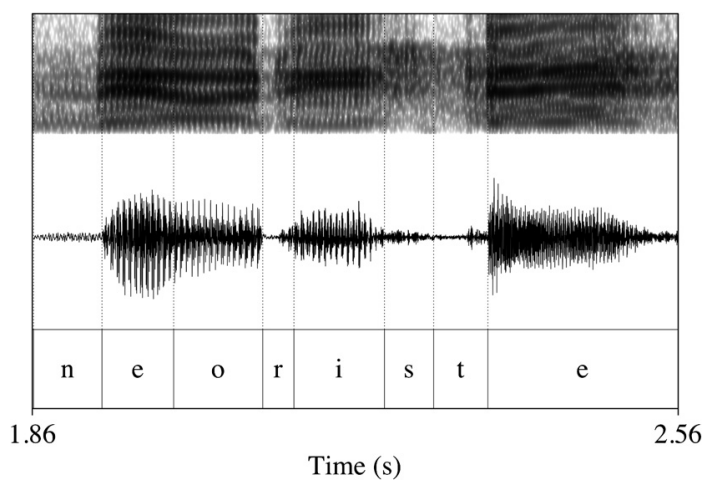

Figure 8. Waveform and spectrogram showing spectral and waveform characteristics of a 11 ne oriste turn (TNM)

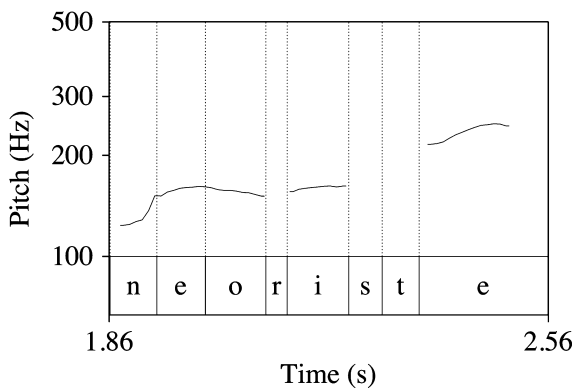

Figure 9. Pitch trace of ne oriste (TNM)

$\mathrm{TL}$ 390

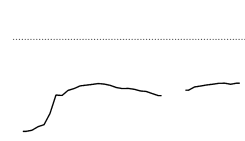

BL 81

Figure 10. Pitch trace of ne oriste, scaled to speaker's range (TNM) 
and abstaining from producing a rise which ends above the middle of the speaker's range the current speaker avoids signalling an upcoming transition relevance place.

\section{Prosodic design of T1 and actions implemented at T2}

There are a variety of turn designs and actions implemented at T2 in Greek phone calls. Following T1 oriste we find the following actions (items in brackets indicate components which may vary):

- [greeting]+candidate recognition of answerer (27/57);

- [greeting]+[candidate recognition of answerer]+caller self identification (9/57);

- greeting (5/57) (includes 'season's greetings');

- greeting+how are you+caller self-identification (4/57)

- ne+[greeting] $(5 / 57)$

- $\left[\right.$ greeting]+switchboard request ${ }^{8}(3 / 57)$;

- direct topic launch (3/57)

- request for answerer identity (1/57).

The distribution of actions following T1 ne is as follows:

- [greeting]+candidate recognition of answerer (8/34);

- [greeting]+[candidate recognition of answerer]+caller self-identification (5/34);

- greeting (8/34) (includes 'season's greetings');

- direct topic launch (1/34);

- $n e[+](6 / 34)$;

- ne+request for answerer identity $(2 / 34)$;

- other $(4 / 34)$.

There is commonality across these two groups of T2. The most frequent component of T2 is candidate recognition of the call answerer; this is present in $54 \%$ of all callers' first turns at T2. The lexical item ne is another component of T2s across the two groups. It is present in $14 \%$ of all callers' first turns at $\mathrm{T} 2$.

Lexical choice of oriste or ne at T1 does not seem to constrain the design of T2. Nor do the T1 pitch contours appear to have an effect on the sequential structure of the rest of the opening. The same kinds of turns occur after both

8 'Switchboard request' refers to a speaker requesting to speak to someone other than the current co-participant (Schegloff 1979). 
oriste and ne, and the same kinds of turns occur after falling and rising final contours. So, for instance we find greeting+candidate answerer recognition+ caller self-identification produced at T2 after both ne (fragment (11)) and oriste (fragment (12)):

(11) GMA

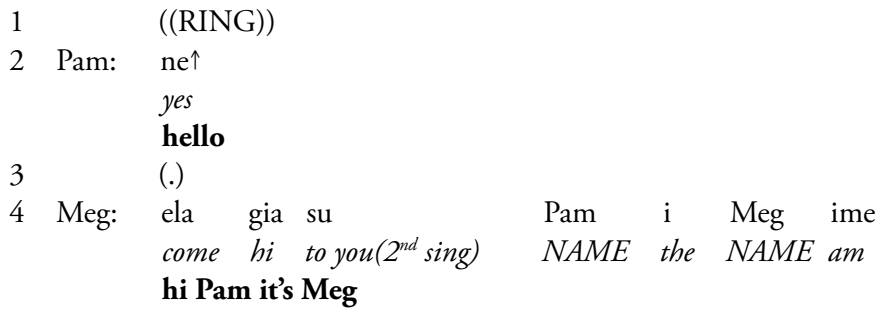

(12) KW

$1 \quad((\mathrm{RING}))$

2 Ian: .h oriste

at your orders

\section{hello}

3 Meg: ela gia su Ian

come hi to you (2 $2^{\text {nd }}$ sing $) \quad$ NAME

hi Ian

4 Meg: I Meg ime

the NAME am

it's Meg

We also find ne (followed by a variety of other talk) at T2 position after both ne (fragment (13)) and oriste (fragment (14)):
(13) $\mathrm{DD}$
$1 \quad$ ((RING)
2 Rex: ne^
yes
hello

3 Meg: .h ne kali hronia ke hronia sas pola

yes good year and years to you $\left(2^{\text {nd }} p l\right)$ many yes happy new year and seasons greetings to you,

4 Meg: i Meg ime

the NAME am

it's Meg

(14) DC

$1 \quad((\mathrm{RING}))$

2 Meg: oriste

at your orders

hello 
3 Amy: ne herete

$$
\text { yes be happy }\left(2^{\text {nd }}\right. \text { pl, imp) }
$$

yes hello

Similarly, we find the greeting+candidate answerer recognition after T1 with falling (fragment (15)) and rising (fragment (16)) final contours:

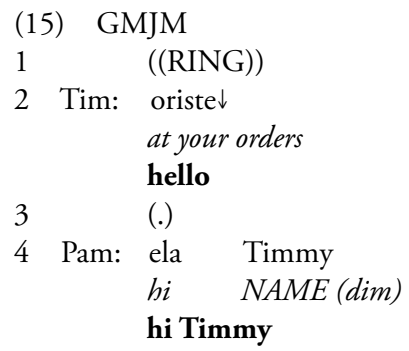

(16) HST

$1 \quad((\mathrm{RING}))$

2 Ron: oriste^

at your orders

hello

3 Tim: .hh (.) ela Ron hronia pola

hi NAME years many

hi Ron best wishes

$4 \quad$ (.) Stavrou

SURNAME

it's Stavrou

We also find direct topic launch after T1 with falling (fragment (17)) and rising (fragment (18)) final contours. For example:

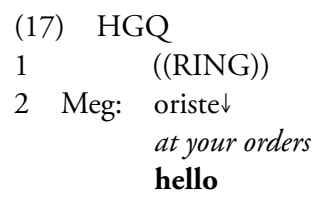

3 Ada: ihes agalitsa ton Stavrou

had (2 $2^{\text {nd }}$ sing, past) embrace (dim) the SURNAME

were you hugging Stavrou

4 Ada: ke se pira

and you (acc) took ( $1^{\text {st }}$ sing)

and I called you?

$5 \quad(0.2)$

6 Meg: ohi kale vlepo ena: sirial

no PART watch one sitcom

no I'm watching a sitcom 
(18) PME

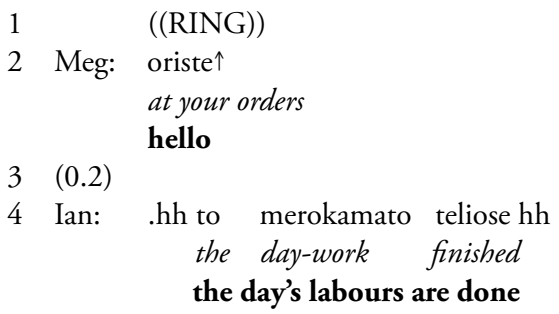

In T1 position in these Greek phone calls, final pitch falls and rises do not appear to be functionally differentiated. They both function in call opening turns which provide a voice sample for the caller and are systematically treated as a 'go ahead' for the caller to take the next turn at talk.

\section{Oriste and ne in non-T1 position}

Oriste and ne may also occur in non-T1 position, and the co-occurring pitch contours may be different from those found in $\mathrm{T} 1$ position. In this section, I briefly explore some of the phonetic and sequential-interactional characteristics of oriste and ne tokens in non-T1 position in the Greek telephone call data. In non-T1 position oriste tokens are only produced with rising pitch while ne tokens are produced with a variety of pitch contours (fall, rise, risefall, level). It should be noted that only tokens with rising pitch are examined in this section for purposes of comparability. By examining this data I aim to explore two main questions:

- whether there is evidence that meaning/function of a specific pitch contour (e.g. a rise) with the same lexical item (e.g. ne) is the same at different places in interactional sequence and

- whether the rises which occur with T1 and non-T1 ne and oriste are phonetically the same - e.g. whether they exhibit the same kinds of alignment and pitch range.

The following fragments provide a sense of the interactional potential of oriste and ne tokens in non-T1 position. The function of oriste and ne in these positions is arrived at by examining the co-participant's response in next turn position to the previous turn featuring the oriste or ne. In fragment (19) oriste functions as a next turn repair initiator (Drew 1994; Schegloff, Jefferson \& Sacks, 1974) as its production at line 4 initiates a next turn by Liz which is a partial repetition of her turn at lines 1-2 in an attempt to resolve the 
understanding issue. In fragment (20) ne functions as a 'continuer' (Schegloff 1982) as it is followed at line 6 by a continuation of the co-participant's turn (notice the use of $k e$, 'and', which links the talk with the previous talk at lines $1-2)$; in fragment (21) it functions as a positive, type confirming response to a yes-no interrogative (Raymond 2000), and in fragment (22) as an understanding check as it gets a confirmation response type by Liz at line 8 . Turns of interest are arrowed:

(19) BCC

1

2

3

$4 \quad \mathrm{REP} \rightarrow$

5

(20) GT

1

2

3

7
Liz: ne lipon .hhh to- e-i- esi den ihes yes so the PART you not had yes well the erm hadn't you
Liz: kani ECDL
made ECDL
done ECDL?

(0.9)

Jay: orise ${ }^{9} \quad$ [oriste $\uparrow$ ]

at your orders at your orders

pardon? pardon?

Liz: [den ihes ] kani ECDL

not had made ECDL

hadn't you done ECDL?

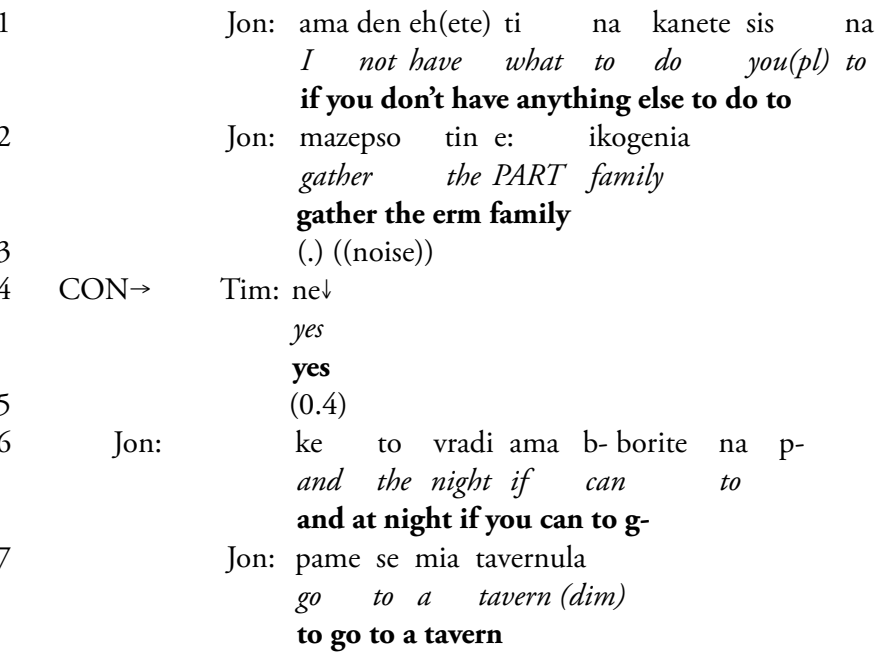

$4 \mathrm{CON} \rightarrow$

5
$6 \quad$ Jon:

9 'Orise' stands for a phonetically not fully realised 'oriste' which in this case is produced without a full alveolar closure. It is subsequently repaired ('oriste') later in the turn. 
(21) ES

1

2 PosR $\rightarrow$

3

4

5

6

9

(22) BNY

1

Liz: Ria esi ise= NAME you are

Ria is that you?

Ria: ne hh

yes

yes

Liz: hh eh heh .hhhh ihe plaka kses

had fun know

it was funny you know

Liz: itan se mia selida ke elege (0.2) pos

was in a page and say(past) how

he was on a website and he was saying

Liz: vgeno apo do

exit from here

how do I get out of here?

Liz: hhhh tu leo $\mathrm{p}$ [u thes] na pas.h

to him say where want to go

I said to him where do you want to go

Jay:

oh ]

PART

oh no

6 CHECK $\rightarrow$ Jay: ne: $\downarrow$

yes

really?

$(0.1)$

Liz: (n)e $m$ gia na vgis eprepe

yes for to exit should have had

yes in order to get out you had

Liz: na pas kapu

to go somewhere

to go somewhere

Table 2 shows a breakdown of the number of instances and kinds of non-T1 oriste and ne tokens examined in this paper.

\subsection{Comparison of the phonetic characteristics of $T 1$ and non-T1 oriste and ne}

This paper has argued that rising and falling T1 oriste tokens did not lead to different uptakes in T2 position. It showed that both were receipted by the same kinds of T2s. Rising and falling pitch associated with this lexical item appear to be in free variation at the T1 place in interactional structure. We might reasonably expect then that oriste tokens in non-T1 positions could also exhibit such pitch contour variation. Though the data is limited - in the current telephone call data there are only three occurrences of standalone-oriste 
Table 2. Breakdown of non-T1 instances of oriste and ne

\begin{tabular}{lr}
\hline Non-T1 nes & N \\
\hline Out of overlap, not followed by more talk (all pitch contours) & 51 \\
Rising, out of overlap (some tokens are followed by more talk) & 28 \\
Rising, out of overlap, followed by more talk & 17 \\
Rising, out of overlap, not followed by more talk & 11 \\
Falling, out of overlap, not followed by more talk & 35 \\
Rise-falling, out of overlap, not followed by more talk & 5 \\
\hline Non-T1 oristes & 3 \\
\hline Rising, out of overlap, not followed by more talk &
\end{tabular}

in non-T1 position - there is no evidence of variation. All three occurrences are produced with an overall rising pitch contour. Despite the sparseness of the data, comparison of non-T1 tokens of oriste with rising T1 tokens of oriste suggests that there are no striking phonetic differences.

Pitch ranges of the rise for the T1 oriste tokens and the non-T1 oriste tokens were calculated. The starting point for the measurements was the beginning of the stressed syllable -ri- and the end point the end of voicing of the final vocoid. The results showed that both kinds of oriste tokens have almost identical pitch ranges with T1 rising oriste tokens having a pitch range of 12 semitones and non-T1 oriste tokens a pitch range of 13 semitones. Figures 11 and 12 show the pitch trace of the T1 oriste token of fragment (23) and figures 13 and 14 show the pitch trace of the non-T1 oriste token of fragment (24). Though some microprosodic differences can be observed, the two interactionally different tokens of oriste have very similar pitch characteristics.

(23) VD

\begin{tabular}{|c|c|c|c|}
\hline 1 & & $((\mathrm{RING}))$ & \\
\hline $\mathrm{T} 1 \rightarrow$ & Deb: & $\begin{array}{l}\text { oriste } \uparrow= \\
\text { at your orders } \\
\text { hello }\end{array}$ & \\
\hline 3 & Meg: & $\begin{array}{l}=\mathrm{e} \quad \text { kalispera } \\
P A R T \text { good afternoon } \\
\text { erm good afternoon Deb }\end{array}$ & $\begin{array}{l}\text { Deb } \\
N A M E\end{array}$ \\
\hline 4 & Meg: & $\begin{array}{l}\text { ke pali kali hronia } \\
\text { and again good year } \\
\text { season greetings again }\end{array}$ & \\
\hline 5 & Meg: & $\begin{array}{lll}\text { I } \quad \text { Meg } & \text { ime= } \\
\text { the } \quad N A M E & \text { am } \\
\text { it's Meg } & \end{array}$ & \\
\hline 6 & Deb: & $\begin{array}{l}\text { gia su Meg }[\mathrm{ti} \\
\text { hi you } N A M E \text { what } \\
\text { hi Meg, what's up? }\end{array}$ & $\begin{array}{l}\text { gine]te } \\
\text { happening }\end{array}$ \\
\hline
\end{tabular}




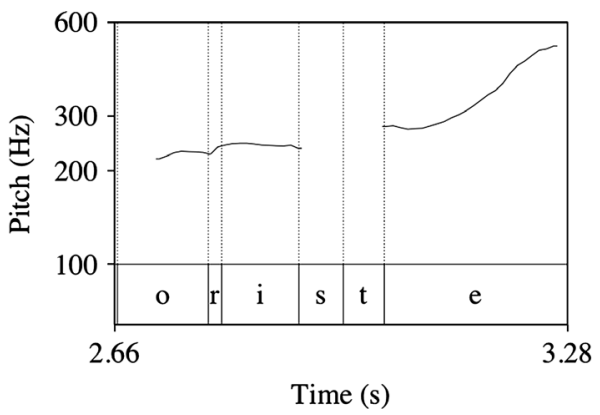

Figure 11. Pitch trace of rising T1 oriste (VD)

TL
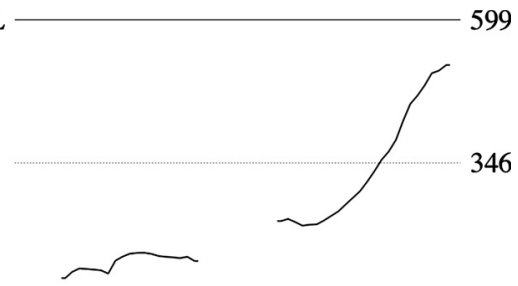

BL 191

Figure 12. Pitch trace of rising T1 oriste, scaled to speaker range (VD)

(24) AW

1

$\begin{array}{llll}\text { Meg: } & \text { e malista o[rea] } & \text { ke esi } \\ & \text { PART perfect beautiful and } & \text { you } \\ & \text { erm okay good many }\end{array}$

2

Ned:

[ke ]

and

3

Meg:

eflhes

and

4

wishes to you too

Ned: $\quad$ [pira $>$ ke to $<$ mesimerak]i

took and the afternoon (dim)

\section{I also called in the afternoon}

5 REP $\rightarrow \quad$ Meg: $\quad$.hhhh oriste $\uparrow$

$$
\begin{aligned}
& \text { at your orders } \\
& \text { pardon? }
\end{aligned}
$$

The results show that the phonetic design of the rising T1 oriste and the rising non-T1 oriste tokens are strikingly similar in their phonetic make-up. Given 


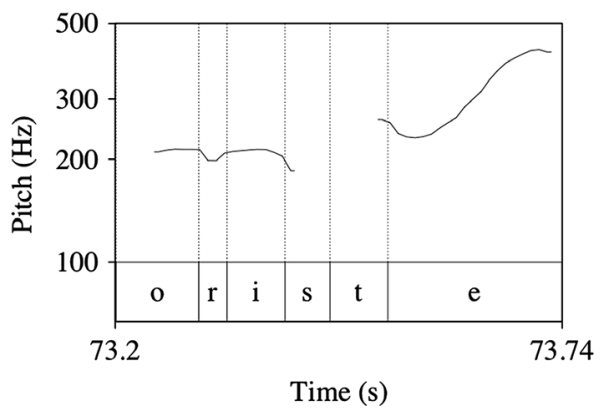

Figure 13. Pitch trace of rising non-T1 oriste (AW)

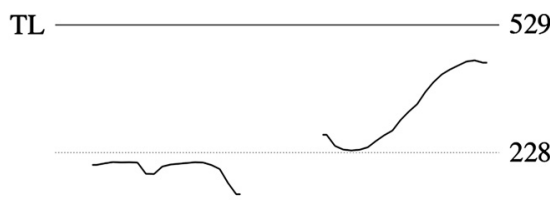

$\mathrm{BL} \longrightarrow 75$

Figure 14. Pitch trace of rising non-T1 oriste, scaled to speaker range (AW)

the small numbers of non-T1 oriste tokens, it is not possible to make statistically robust claims about any observed differences.

\section{2. $T 1$ and non-T1 ne}

A thorough search of the data revealed some 500 instances of ne produced in non-T1 position. The bulk of these are produced in overlap with another speaker's talk; there are also instances of turns consisting of multiple tokens of $n e$, and many of these ne tokens are preceded and/or followed by more talk by the same speaker. For purposes of comparability - in terms of pitch - with the T1 ne tokens, only non-T1 tokens of ne which are produced out of overlap with rising pitch are considered here. There are 28 such instances, 17 of which are followed immediately in the same turn by more talk from the same speaker. These 28 tokens are compared with the T1 ne tokens (34 instances) in an attempt to determine any phonetic similarities or differences between the two groups. 
The pitch range and $\mathrm{F}_{0}$ alignment (i.e. the turning point in rising tokens of ne) were calculated. The results showed that the average pitch range for T1 ne is wider than for non-T1 ne tokens by 3 semitones (T1: mean $=12 \mathrm{st}$, $\max =$ $24 \mathrm{st}, \min =6 \mathrm{st}, \mathrm{SD}=4$; non-T1: mean $=9 \mathrm{st}, \max =31 \mathrm{st}, \min =1 \mathrm{st}, \mathrm{SD}=7$ ). This difference, though, is not significant. To see if $\mathrm{F}_{0}$ alignment differences obtain between $\mathrm{T} 1$ and non-T1 ne, and to determine whether any such differences might be related to possible differentiation of function, the TP was computed for the two types. Results indicate that on average the TP occurs earlier in non-T1 ne tokens than in T1 tokens: non-T1: $41.7 \mathrm{~ms}$ after the onset of the vocoid $(\max =155 \mathrm{~ms}, \min =-0.03 \mathrm{~ms}, \mathrm{SD}=0.52)$; T1 tokens: $75.4 \mathrm{~ms}$ after the onset of the vocoid $(\max =121 \mathrm{~ms}, \mathrm{~min}=13 \mathrm{~ms}, \mathrm{SD}=28)$. This difference is statistically significant: $\mathrm{t}=2.9133(\mathrm{df}=34.872$, $\mathrm{p}$-value $=0.006)$.

\subsection{Interim conclusions}

So far it has been shown that the phonetic design of rising non-T1 oriste is virtually identical to the rising $\mathrm{T} 1$ tokens in terms of pitch. It has also been shown that a rising pitch contour with the lexical item ne may have a different phonetic shape when $n e$ is located in turns other than T1. The results for ne are quite different. In $\mathrm{T} 1$ position, ne is always produced with a rising contour. In non-T1 position, rising tokens of ne seem to have a different phonetic shape in terms of pitch range and pitch alignment. This may have to do with the multifunctionality of the lexical item $n e$ as it does not seem to generalise to oriste which is semantically less flexible ${ }^{10}$. Alternatively, these findings suggest that there may be a connection between phonetic form and place in structure/function.

The fact that there is a difference in the alignment of the turning point of the rise of T1 and non-T1 ne tokens is potentially of phonological consequence. Researchers working on pitch who have adopted an autosegmental approach, have made a number of observations about the linguistic implications of differing pitch contour alignment (such as a turning point in the pitch movement) with the segmental and lexical material (Arvaniti et al. 2006; Gósy and Terken 1994). For instance, Gósy and Terken (1994) have argued that differences in pitch peak alignment may discriminate between declaratives and interrogatives in Hungarian while D'Imperio and House (1997) make a similar claim for Neopolitan Italian. Recently, Arvaniti et al. (2006) have argued that alignment of rising-falling contours with the segmental material is different in Greek polar questions and contrastive statements (Arvaniti et al. 2006: 437).

${ }^{10}$ I would like to thank one anonymous reviewer for this suggestion. 
In the current data, alignment of rising pitch in non-T1 ne tokens is found to vary in a manner not unlike that described by Lickley et al. (2005). Lickley et al. find that the alignment of low $\mathrm{F}_{0}$ TPs in Dutch falling-rising questions is 'affected by the location of a postnuclear secondary stressed syllable if one is present' (2005: 157). In the case of non-T1 ne tokens, early or late alignment of the TP of the rise seems to be related to the composition of the ne turn and the presence, or not, of any talk following ne. The TP of the rise of many of the ne tokens followed by more talk occurs noticeably earlier than the TP in T1 ne. This early TP with rising ne occurs irrespective of the lexical and accentual make-up of the following talk. Figure 15 illustrates a case where the TP of the rise associated with ne occurs during the nasal portion as opposed to all of the T1 ne where it occurs during the vowel. Moreover, the highest pitch point occurs during the rise and where $n e$ is followed by more talk, the main pitch event of the intonational phrase is also the rising contour associated with ne. Figure 16 presents a pitch trace of a typical 'late aligned' T1 ne and Figure 15 a typical 'early aligned non-T1 token produced by the same speaker.

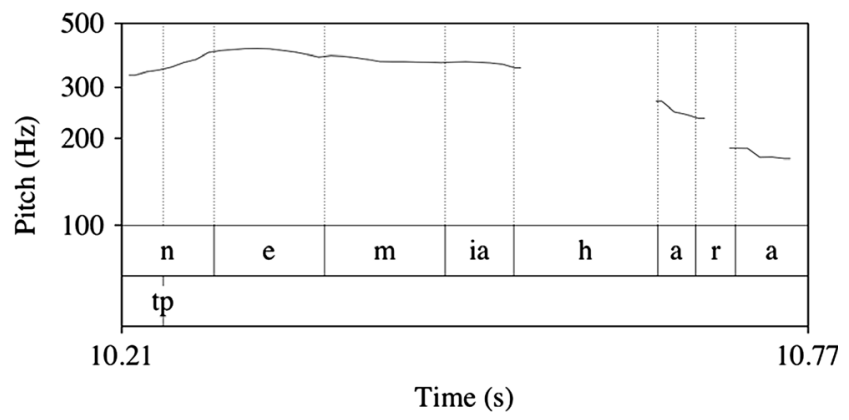

Figure 15. Early aligned TP, non-T1 ne (BCC)

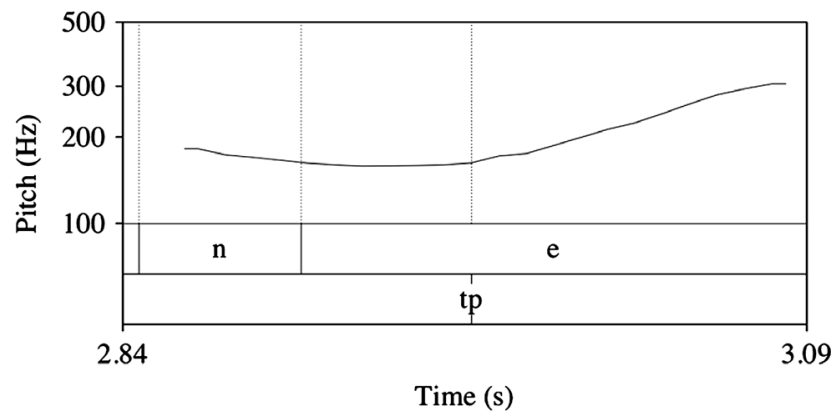

Figure 16. Late aligned TP, T1 nes (MTL) 
The $\mathrm{T} 1$ token is longer and has a greater pitch range (range $=11 \mathrm{st})$ than the non-T1 token which is followed by more talk (range $=3 \mathrm{st}$ ). In standalone T1 ne tokens, TPs of rises align later in the word, while in non-T1 tokens followed by more talk, the TPs occur earlier (often within the nasal portion). Judgment is deferred about any phonological/functional claims, however, because the difference in alignment may turn out to be an artifact of having compared sequentially non-comparable cases of the lexical item ne. The following section attempts to shed some more light on the question of alignment of turning points of T1 and non-T1 rising ne tokens.

\subsection{Standalone, non-overlapped, non-T1 ne}

In the previous section, the issue of comparing potentially incomparable cases of data was raised. This section attempts a comparison of sequences with the same interactional structure in an attempt to determine whether this has any effect on the findings reported so far for the prosodic detail of T1 and non-T1 $n e$ tokens. It is also considered whether early alignment is indeed a feature of non-T1 ne tokens irrespective of whether these are followed by more talk or not. A thorough search of the corpus was made for ne tokens which were in non-T1 position, out of overlap and were not preceded and/or followed immediately by more talk by the same speaker. There are 51 instances. Of these 35 have falling pitch contours, 11 have rising contours and 5 have risingfalling contours. Analysis of the 11 instances of out of overlap tokens of standalone ne produced with rising pitch gives rather different results from those reported in the previous section.

An examination of the TP of the rising contour in the standalone non-T1 ne tokens and the $\mathrm{T} 1$ tokens indicates that it occurs somewhat earlier in the vocoid for T1 ne than for standalone, non-T1 ne (T1 TP from onset of vocoid: mean $=75 \mathrm{~ms}, \max =120 \mathrm{~ms}, \min =13 \mathrm{~ms}, \mathrm{SD}=27$; standalone non-T1 TP from onset of vocoid: mean $=97 \mathrm{~ms}, \max =144 \mathrm{~ms}, \min =27 \mathrm{~ms}, \mathrm{SD}=38$ ). However, this difference is not statistically significant. Standalone non-T1 ne and T1 ne display similar pitch ranges $(\mathrm{T} 1$ ne: mean $=12 \mathrm{st}, \max =24 \mathrm{st}, \mathrm{min}=$ $6, \mathrm{SD}=4$; non-T1 ne: mean $=12 \mathrm{st}, \max =16 \mathrm{st}, \min =7 \mathrm{st}, \mathrm{SD}=3)$. Again, the differences are not statistically significant.

The results reported so far raise several issues about alignment and what triggers it, as well as about interactional structure and its potential consequences for issues of phonological contrast. The findings indicate that if we consider only standalone non-T1 ne tokens produced with rising contours and compare these with T1 ne tokens there is no difference in the alignment of the rise between the two sets. This goes some way toward confirming that the differences found between pitch alignment in T1 ne with rising contours 
and non-T1 tokens are indeed associated with the composition of particular turns - an early aligned TP in a non-T1 ne produced with a rising pitch contour is part of the projection of more talk to come. A second conclusion we can draw is that it is risky to make overall phonological statements about possibly non-similar - non-comparable linguistic objects. Not only do we need to take into account the lexical and phonetic information when we make comparisons, but also we should consider other factors - such as the action which a turn accomplishes and its interactional context - which may affect the results.

\section{Interactional function and phonetic design}

\subsection{Non-T1 oriste: next turn repair initiator}

Examination of the transcribed Greek data revealed only three instances of the lexical item oriste in positions other than the first responsive turn at the beginning of telephone conversations. All three occur 'standalone' in a turn without any talk preceding or following them. All do the same action: initiating repair (see Drew 1997). Relevant turns are indicated by 'REP $\rightarrow$ ' following the line number. Fragments (25) and (26) illustrate:

(25) AW

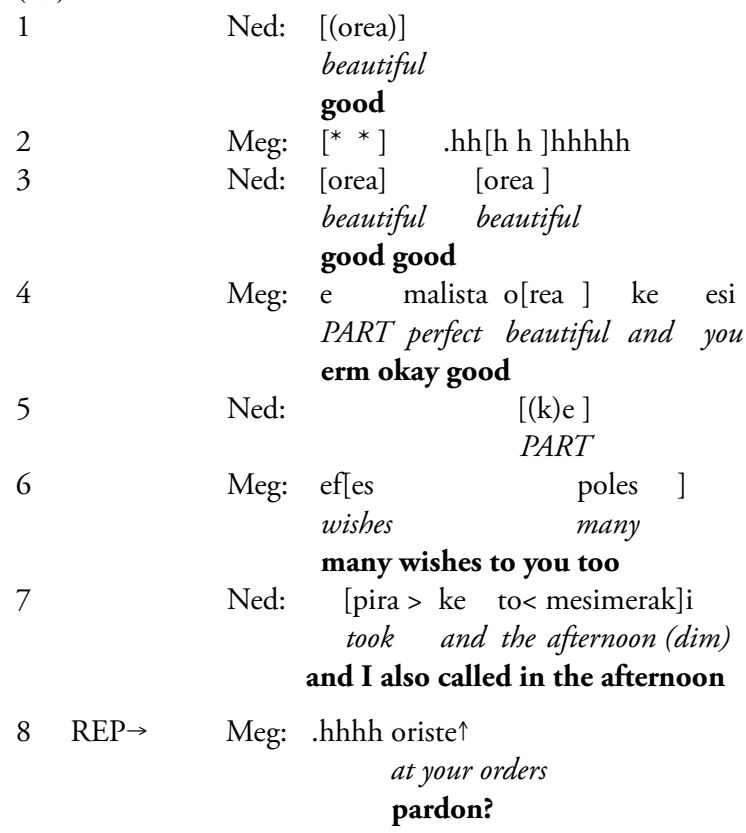


9

10

11

12

13

14
$(0.2)$

$\begin{array}{lll}\text { Meg: } & \mathrm{n}[\mathrm{e}] \\ & \text { yes } & \\ & \text { yes } & \\ \text { Ned: } & {[\text { pira }] \text { to }} \\ & \text { took the } \\ & \text { I called in }\end{array}$

\section{I called in}

[mesimeri (ke) den itan kanenas]

noon and not were no one

the afternoon and no one was there

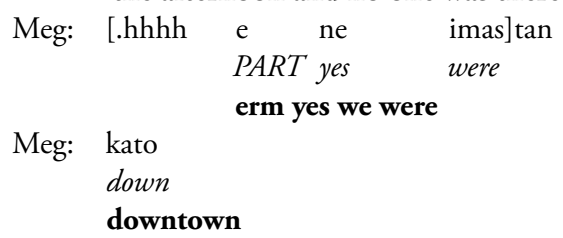

Fragment (25) is taken from a telephone conversation between two friends during the Christmas holidays. Immediately prior to this sequence, Meg and Ned have been exchanging wishes for the New Year and Ned has enquired whether both Meg's children have come home. This enquiry generates a short interchange in which Meg reminds Ned that she had previously told him that only one of her children would be at home. Ned acknowledges this, and at lines 1-3 the participants collaborate on bringing the sequence to a close. Meg's turn at lines 4-6, in which she reciprocates Ned's best wishes, is overlapped by Ned with what looks like a possible complaint-implicative turn. This turn offers the (new) information that he had tried to phone earlier in the day. Meg's next turn at line 8 initiates repair and Ned redoes his talk at lines 11-12 adding the information that when he called there was no one there. Meg responds in overlap with the end of this turn and offers an account for why the phone was not answered ('we were downtown'). The oriste token here, begins with a glottal stop followed by a short period of creaky voice and is produced with a noticeably rising contour (the majority of the rise occurs during the last two-thirds of the final syllable).

Fragment (26) comes from a call between two family members. As we join the sequence, Liz has just come back to the phone after suddenly passing it over to another family member. At lines 1-2 and 4 she apologises and provides an account of why she terminated abruptly their conversation earlier on - she had a coughing fit.

(26) BCC

$$
\begin{aligned}
& \text { Liz: } \mathrm{m} \text { ela sorry } \\
& \text { PART come sorry } \\
& \text { hi sorry }
\end{aligned}
$$




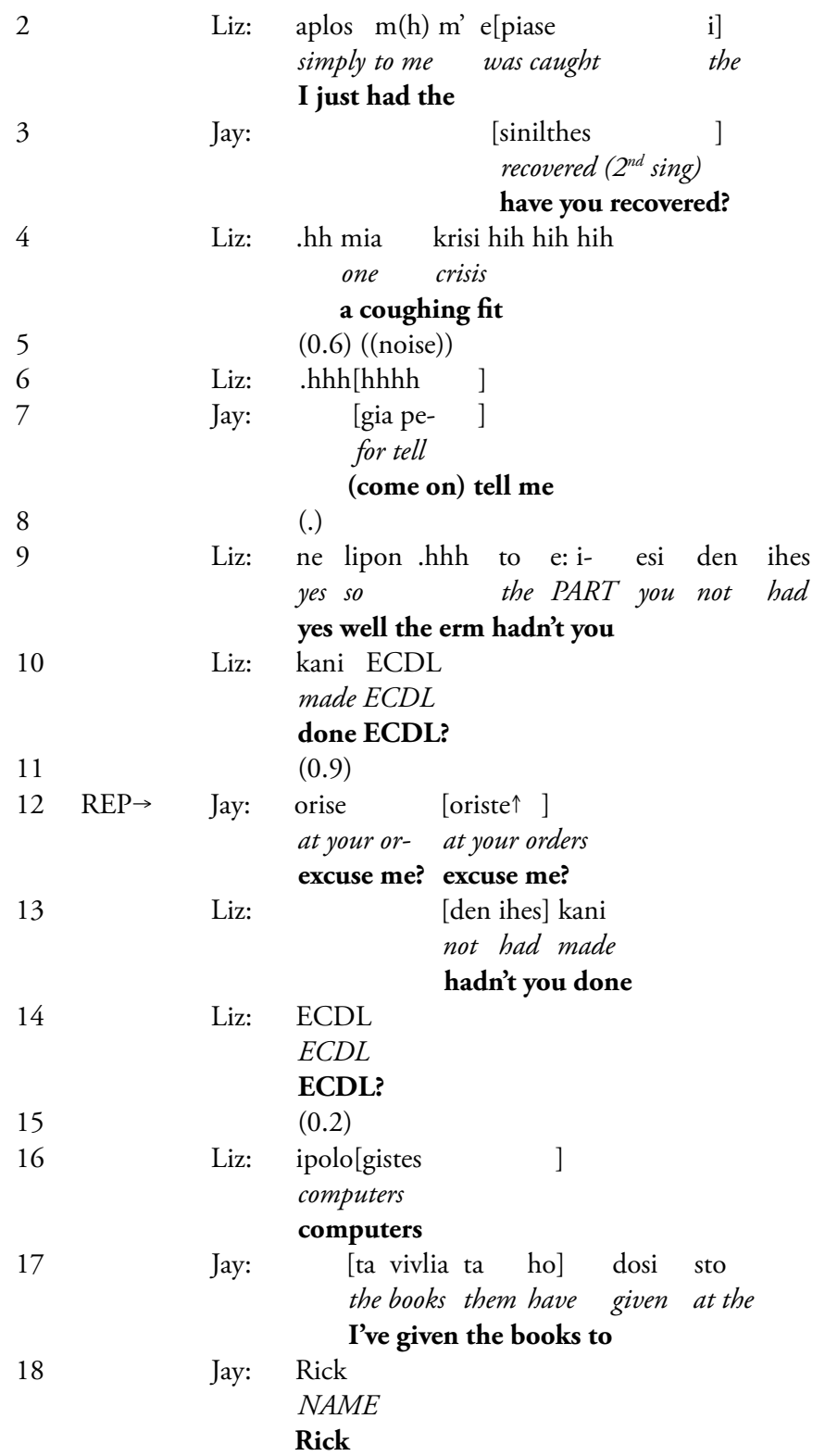

At line 3, Jay enquires whether Liz has recovered, but does not get an immediate response. He pursues his enquiry at line 7 , which Liz addresses minimally with 'yes' at the beginning of her turn at line 9. She follows this with talk 
which changes the topic of the talk. Like Ned's turn at lines 5 and 7 in fragment (26) Liz's turn is not directly connected to the immediately prior talk. Her enquiry about whether Jay had taken the European Computer Driving Licence (ECDL) qualification is treated by him as problematic with the production of two oriste tokens with rising pitch. Following Jay's repair initiation, Liz redoes her enquiry — which Jay appears to treat (line17) as an indirect way of asking to borrow text books associated with the ECDL course ('I've given the books to Rick ... you want them?'). In these fragments the lexical item oriste has a noticeably different interactional function from that which it has in the first turn of telephone calls. In T1 position, it functions as a response to the summons. Here it is clearly treated as a repair initiator. All three cases of non$\mathrm{T} 1$ oriste in the telephone data are treated in this way. All are produced after a turn which is not topically connected to the preceding talk and all are followed by a re-doing of the trouble source turn. All three are produced with a rising pitch contour.

Interestingly, the phonetic characteristics of the re-doings appear to pattern in the same way as the 'disjunct' repetition repairs described by Curl (2005). According to Curl, disjunct repetition repairs (where the material which gets repeated was interactionally 'disjunct' from the prior talk) were found to have 'non-upgraded' phonetics with reference to the first mention. They were no louder or longer, their articulatory setting was similar to the previous talk as was their pitch range. These repetition repairs differ from what she describes as 'fitted' repetition repairs which were found to have 'upgraded' phonetics. She suggests that her results call for the need to refine the idea that repetition is linked with phonetic reduction and proposes that sequential placement of talk should be taken into consideration as well.

\subsection{Non-T1 ne}

Compared with the few tokens of oriste in non-T1 position, the Greek telephone call data yielded 51 occurrences of standalone, non-T1, out of overlap ne tokens (henceforth SA, non-T1). Sequential analysis suggests that these standalone non-T1 ne tokens may have a variety of interactional functions. The most frequent are as:

1. continuers;

2. acknowledgements;

3. positive responses to enquiry.

The remainder of this section considers some cases of ne tokens employed as continuers. 


\subsection{Continuers}

Fragments (27) and (28) exemplify cases where ne is treated as a continuer (Gardner 1997; Schegloff 1982). Relevant turns are indicated by 'CON $\rightarrow$ ' following the line number. By 'continuer' is meant a minimal receipt of some immediately prior talk which passes up on an opportunity to produce a longer, responsive turn and thus displays an orientation that a not-as-yetcompleted spate of talk is in progress. In terms of sequential placement, these tokens occur around what might be termed 'partial completion' (Gardner 1997: 143).

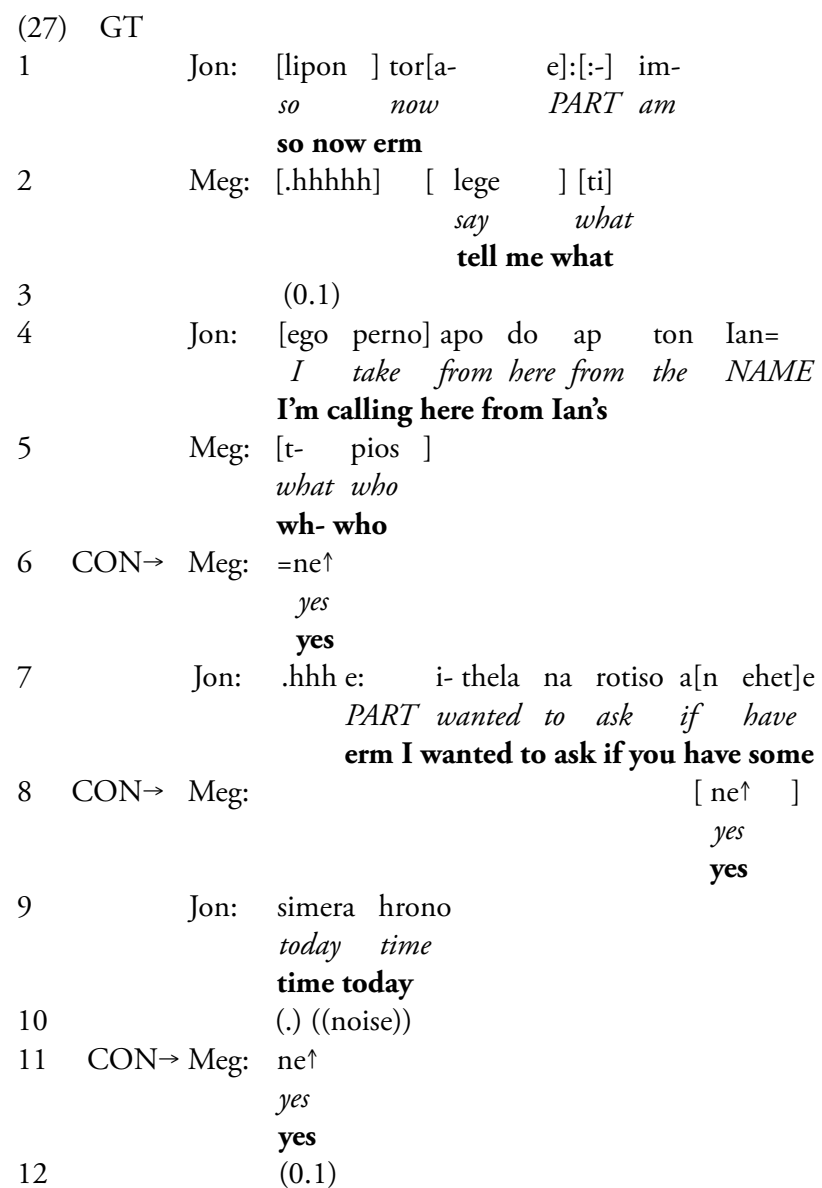


13

Fragment (27) begins some 40 seconds into a telephone call between two relatives. Jon's turn at line 1 is an attempt to launch a topic which is the reason for his call. This gets a 'go ahead' in overlap from Meg (line 2). After a short pause (0.1) Jon has another stab at starting his 'telling' at line 4. His turn is syntactically and semantically complete but prosodically and pragmatically incomplete - more is projected. Meg receipts this turn with a minimal ne which functions as a continuer/go ahead for Jon. Jon then resumes his telling at line 7 which is prefaced by a hedge and is designed as a pre 'I wanted to ask. . .'. Meg produces another $n e$ in overlap with the beginning of Jon's second TCU which is also part of the pre 'if you have time today'. After this second part which is also syntactically and semantically complete but not prosodically or pragmatically complete, Meg produces yet another ne continuer/go ahead for Jon. After a brief gap, Jon continues his turn which evolves into an invitation to dinner. It is designed with an initial 'and' which explicitly links it to his previous talk (Local and Walker 2004). This turn, like the ones preceding it, is syntactically but not prosodically complete and projects more talk to come. After a short pause $(0.2$ secs) Meg receipts the turn with $n e$ which is again designed to be heard as a continuer and is treated as such: it is followed by more talk by her co-participant which is again linked to his previous talk with ke, 'and'.

Fragment (28) is taken from the same telephone call as fragment (27). It occurs 37 seconds later in the call, after Meg has handed over the phone to Tim, another family member. After a series of greetings and reciprocated 
how-are-yous at lines 1-2, Jon produces a turn which is syntactically, pragmatically, semantically and prosodically incomplete. He produces two TCUs ('lipon kitakse' ('so look') and 'e ipame do me ton Ian' ('erm we said here with Ian')) the second of which is syntactically incomplete as the complement is missing. It is also pragmatically incomplete, as Tim does not know what Jon and Ian have said to one another, and prosodically incomplete, as the turn ends with a final rising pitch contour. At line 3 , Tim receipts this turn with ne followed by a short 0.2 seconds pause after which Jon continues with his turn, telling Tim what he and Ian were thinking of doing which was to 'gather the family up'. Tim receipts this with another ne at line 8 , which is treated as a continuer by Jon at lines 10-11 where he produces the next part of his plan for the evening (constructed with an initial 'ke', 'and').

(28) GT

$\begin{array}{ll}\text { Jon: } & \text { Ian } \\ & \text { NAME }\end{array}$

$3 \mathrm{CON} \rightarrow$ Tim: ne $\downarrow$

yes

yes

$4 \quad(0.2)$

5 Jon: ama den eh(ete) ti na kanete sis na

if not have(pl) what to do(pl) you(pl) to

if you don't have anything else to do to

6 Jon: mazepso tin e ikogenia

gather the PART family

gather the erm family up

$7 \quad$ (.) ((noise))

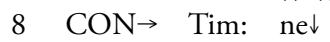

yes

yes

$9 \quad(0.4)$

10 Jon: ke to vradi ama b- borite na p-

and the night if can to

and at night if you can to $\mathrm{g}$ -

11 Jon: pame se mia tavernula

go to a tavern (dim)

to go to a tavern

12

$(0.2)$

The ne tokens functioning as continuers in fragment (27) all exhibit similar phonetic characteristics: they are all produced with rising pitch contours 
which have a late alignment of the TP of the rise. However those in fragment (28) at lines 3 and 8 , although also functioning as continuers, are produced with a falling pitch contour. There does not appear to be anything particularly distinctive about these falling ne tokens functioning as continuers. They are not noticeably high or low in the speaker's pitch range, are not noticeable long, nor do they exhibit ranges of articulatory variation or phonatory behaviour which might distinguish them from the falling acknowledgment ne tokens (both acknowledgements and continuers may have relatively long nasal portions, both may be done with creaky voice, for instance). The $\mathrm{F}_{0}$ range for ne continuers with rising contours is: $\min =8 \mathrm{st}, \max =17 \mathrm{st}$, mean $=13 \mathrm{st}$, $\mathrm{SD}=3$; while the range for ne continuers with falling contours is: $\min =8 \mathrm{st}$, $\max =11$ st, mean $=9 \mathrm{st}, \mathrm{SD}=2$.

Fragments (27) and (28) then, illustrate the fact that different pitch contours may be used in the implementation of the same function - in this case, that of a continuer - and that what matters is the sequential context in which talk is produced.

The sequences explored indicate that standalone non-T1 tokens of oriste and $n e$ can have very different interactional functions from tokens of the same lexical items occurring in $\mathrm{T} 1$ position. However, despite the fact that oriste may act as a next turn repair initiator, it may have the same pitch characteristics (i.e., rise) as oriste tokens found in T1 position. Similarly, consideration of continuer sequences involving standalone non-T1 ne suggests that they may be produced with either rising or falling pitch contours. These findings point to the conclusion that the meaning/function of pitch events cannot be straightforwardly arrived at. There are overlaps of pitch contour types across interactional function as well as various pitch shapes associated with a single lexical item (e.g. ne). The findings also show that different functions can be accomplished by employing the same lexical item with the same pitch contour type at a different place in conversational structure.

\section{Conclusion}

Results show that the lexico-syntactic design of a turn is consequential for its phonetic design. In Greek T1 turns, the choice of lexical item (oriste or ne) predicts and constrains the choice of pitch contour for that turn. Although choice of final falling or rising contours was associated with different lexical items, there was no evidence to suggest that this conditioned what actions were done in next turn position. One conclusion that was drawn from this was that at this place in interactional structure (T1), final falling and rising contours are in free variation. While it is often assumed that final falling and 
final rising contours give rise to different meanings and therefore contrast phonologically (see e.g. Beckman et al. 2005; Fletcher et al. 2005; Ladd 1996) if attention is paid to where particular contours appear in sequential structure, and if the next sequential action is allowed to play a role in specifying the function of a prior turn, there may not be any interactional evidence to support a claim for contrastive status (or functional differentiation) (see also Golato et al. 2008 and Betz et al. 2008 who show that different alignments of falling contours and different prosodic patterns associated with tokens such as $j a j a$, and achja have different interactional functions). One implication of this is that we need to be cautious in making a priori assumptions about how we interpret the functional import of pitch differences.

The same lexical items in other than $\mathrm{T} 1$ position display more variability in their phonetic design. It was also shown that the same kind of pitch contour (e.g. a rise) associated with the same lexical item (e.g. oriste) could perform different functions. These results suggest that researchers need to be wary of comparing seemingly comparable data based just on lexical identity or similarity of phonetic design. It is not only the lexical and phonetic information that we need to take into account when comparing data sets. It would seem analytically more robust to establish comparability in terms of interactional function and place in interactional structure. If we do not, we may arrive at the wrong conclusions, and construct claims about, for instance, phonological function on the basis of non-comparable cases.

The findings documented in this article have more general empirical and theoretical implications for research on prosodic features of speech. In particular they take a somewhat broader view of 'context' than is routine in studies of pitch phenomena and suggest that if sequential-interactional structure and participant orientation are taken into account when functional matters are considered, it is possible to develop a different kind of account of the role of pitch in everyday talk. That is, it becomes possible to address issues of phonetic variability and its functional implications by specifying 'context' in a way which provides for a participant-centred understanding of what stretches of talk can be considered linguistically comparable. By examining the way pitch features function at particular places in the sequence of turns-at-talk, it has been possible to reveal places where particular choices of pitch contour are not available to speakers (e.g. T1 ne only permits final rising contours).

\section{Acknowledgements}

I would like to thank John Local and three anonymous reviewers for their comments and suggestions. 


\section{References}

Abercrombie, David. 1967. Elements of General Phonetics. Edinburgh: Edinbrugh University Press.

Antonopoulou, Eleni and Maria Sifianou. 2003. Conversational dynamics of humour: the telephone game in Greek. Journal of Pragmatics 35: 741-769.

Arvaniti, Amalia, and Mary Baltazani. 2005. Intonational analysis and prosodic annotation of Greek spoken corpora. In Sun-Ah Jun (ed) Prosodic typology: The phonology of intonation and phrasing, 84-117. Oxford: Oxford University Press.

Arvaniti, Amalia, D. Robert Ladd, and Ineke Mennen. 2006. Tonal association and tonal alignments: evidence from Greek polar questions and contrastive statements. Language and Speech 49: 421-450.

Babiniotis Giorgos. 1998. Concise History of the Greek Language. (In Greek). Athens.

Baltazani, Mary. 2006. Intonation and pragmatic interpretation of negation in Greek. Journal of Pragmatics 38: 1658-1676.

Beckman, Mary E., Julia Hirschberg, and Stefanie Shattuck-Hufnagel. 2005. The original ToBI system and the evolution of the ToBI framework. In Sun-Ah Jun (ed.) Prosodic typology: The phonology of intonation and phrasing, Cambridge: University Press.

Betz, Emma. and Golato, Andrea. 2008. Remembering relevant information and withholding relevant next actions: The German token achja. Research on Language and Social Interaction 41(1): 58-98.

Browning, Robert. 1983. Medieval and Modern Greek. Cambridge University Press: Cambridge.

Charalambakis Christophoros. 1992. Modern Greek Language (in Greek). Athens: Nefeli.

Couper-Kuhlen, Elizabeth. 2001. Interactional prosody: High onsets in reason-for the-call turns. Language in Society 30: 29-53.

Curl, Traci S. 2005. Practices in Other-Initiated Repair Resolution: The Phonetic Differentiation of 'Repetitions'. Discource Processes 1-43.

Danby, Susan, Carly W. Butler and Michael Emmison. 2009. 'When 'listeners can't talk': Comparing active listening in opening sequences of telephone and online counseling', Australian Journal of Communication, 36/3: 91-114

D'Imperio, Mariapaola, and David House. 1997. Perception of questions and statements in Neopolitan Italian. In Eurospeech '97: Proceedings of the European Conference on Speech Communication and Technology, 251-254.

Drew, Paul. 1994. Conversation Analysis. In Encyclopedia of language and linguistics volume 2: 749-754. Oxford: Pergamon Press.

Drew, Paul. 1997. 'Open' class repair initiators in response to sequential sources of troubles in conversation. Journal of Pragmatics 28: 69-101.

Drew, Paul. 1998. 'Open' class repair initiators in response to sequential sources of troubles in conversation. Journal of Pragmatics 28: 69-101.

Fletcher, Janet, Esther Grabe, and Paul Warren. 2005. Intonational variation in four dialects of English: the high rising tune. In Prosodic typology: The phonology of intonation and phrasing, 390-409. Oxford: Oxford University Press.

Gardner, Rod. 1997. The Conversation Object Mm: A Weak and Variable Acknowledging Token. Language and Social Interaction 30: 131-156.

Golato, Andrea. and Fagyal, Zsuzsanna. 2008. Comparing single and double saying of the German response token ja and the role of prosody - A conversation analytic perspective. Research on Language and Social Interaction 41(3): 1-30.

Goodwin, Charles and John Heritage. 1990. Conversation Analysis. Annual Review of Anthropology 19: 283-307 
Gósy, Mária, and Jacques Terken. 1994. Question marking in Hungarian: timing and height of pitch peaks. Journal of Phonetics 22: 269-281.

Heritage, John. 1984. Garfinkel and ethnomethodology. Cambridge: Polity.

Houtkoop-Steenstra, H. 1991. Opening sequences in Dutch telephone conversations. In Talk and social structure, ed. D. Boden and D. H. Zimmerman, 232-250. University of California Press.

Hutchby, Ian and Robin Wooffitt. 1998. Conversation analysis. Cambridge: Polity.

Jefferson, Gail. 1973. A case of precision timing in ordinary conversation: Overlapped tagpositioned address terms in closing sequences. Semiotica 9: 47-96.

Ladd, D. Robert. 1996. Intonational phonology. Cambridge: Cambridge University Press.

Lickley, Robin, Astrid Schepman, and D. Robert Ladd. 2005. Alignment of "phrase accent" lows in Dutch falling rising questions: theoretical and methodological implications. Language and Speech 48: 157-183.

Local, John. 2007. Phonetic detail and the organisation of talk-in-interaction. In XVIth International Congress of Phonetic Sciences, Saarbrücken, Germany, 1-10.

Local, John and Gareth Walker. 2004. Abrupt-joins as a resource for the production of multiunit, multi-action turns. Journal of Pragmatics 1375-1403.

Mackridge, Peter. 1985. The Modern Greek Language: A Descriptive Analysis of Standard Modern Greek. Oxford: Clarendon Press.

Pavlidou, Theodossia. 2000. Telephone conversations in Greek and German: Attending to the relationship aspect of communication. In H. Spencer-Oatey (ed.) Culturally speaking, 121142. Continuum.

Pike, Kenneth Lee. 1943. Phonetics: A Critical Analysis of Phonetic Theory and a Technic for the Practical Description of Sounds. Ann Arbor: University of Michigan Press.

Raymond, Geoffrey. 2000. The structure of responding: Type-conforming and nonconforming responses to yes/no type interrogatives. Doctoral Dissertation, University of California Los Angeles.

Sacks, Harvey, Emanuel A. Schegloff, and Gail Jefferson. 1974. A simplest systematics for the organization of turn-taking for conversation. Language 50: 696-735.

Sacks, Harvey. 1992a. Lectures on conversation, volume II. Oxford: Blackwell.

Sacks, Harvey. 1992b. Lectures on conversation, volume I. Oxford: Blackwell.

Schegloff, Emanuel A. 1979. Identification and recognition in telephone conversation openings. In George Psathas (ed.), Everyday language: Studies in Ethnomethodology, 23-77. New York: Irvington.

Schegloff, Emanuel A. 1982. Discourse as an interactional achievement: Some uses of 'uh huh' and other things that come between sentences. In Deborah Tannen (ed.) Georgetown university round table on linguistics 1981. Analysing discourse: Text and talk, 71-93. Washington: Georgetown University Press.

Schegloff, Emanuel A. 1986. The routine as achievement, Human Studies 9: 111-151.

Schegloff, Emanuel A. 2000. Overlapping talk and the organization of turn-taking for conversation. Language in Society 29: 1-63.

Szczepek Reed, Beatrice. 2009. Prosodic orientation: A practice for sequence organisation in broadcast telephone openings. Journal of Pragmatics 41: 1223-1247

ten Have, Paul. 1999. Doing conversation analysis: A practical guide. London: Sage.

Tzitzilis, Christos. 2000. Modern Greek Dialects and Modern Greek Dialectology (in Greek). In Language Encyclopedia,15-22. Thessaloniki: Centre for the Greek Language.

Welby, P., and H. Loevenbruck. 2006. Anchored dow in anchorage: Syllable structure and segmental anchoring in french. Italian Journal of Linguistics 18: 73-124.

Xu, Y. 1998. Consistency of tone-syllable alignment across different syllable structures and speaking rates. Phonetica 55: 179-203. 


\section{Appendix A: Transcription conventions}

Additional to the CA conventions for transcribing conversational extracts, the following conventions are also employed in the transcripts and their glosses:

$\begin{array}{ll}\uparrow & \text { indicates an overall final rising pitch } \\ \downarrow & \text { indicates an overall final falling pitch } \\ 1^{\text {st }} \text { sing } & \text { first person singular } \\ 3^{\text {rd }} \text { sing } & \text { third person singular } \\ 2^{\text {nd }} \text { sing } & \text { second person singular } \\ 2^{\text {nd }} \mathrm{pl} & \text { second person plural } \\ \text { past } & \text { past tense } \\ \text { sing } & \text { singular } \\ \text { pl } & \text { plural } \\ \text { fem } & \text { feminine } \\ \text { acc } & \text { accusative } \\ \text { imp } & \text { imperative } \\ \text { dim } & \text { diminutive } \\ \text { PART } & \text { particle } \\ * & \text { unintelligible syllable }\end{array}$

